\title{
Increasing Water Intake in Chronic Kidney Disease: Why? Safe? Possible?
}

\author{
William F. Clark ${ }^{a}$ Jessica M. Sontrop ${ }^{b}$ Louise Moist ${ }^{a}$ b $\quad$ S.-H. Huang ${ }^{a}$ \\ ${ }^{a}$ Division of Nephrology, Department of Medicine, London Health Sciences Centre, and \\ ${ }^{b}$ Department of Epidemiology and Biostatistics, Western University, London, Ont., Canada
}

\section{Key Words}

Water · Chronic kidney disease · Pilot study · Randomized controlled trial $\cdot$ Antidiuretic hormone $\cdot$ Water intake

\begin{abstract}
Increased water intake may slow the progression of chronic kidney disease by lowering vasopressin levels. Prior to initiating a large randomized controlled trial on the effect of increased water intake on renal decline, we conducted a six-week pilot study to examine the safety and feasibility of asking adults with chronic kidney disease to increase their water intake. We randomly assigned 29 patients to either a hydration or a control group. The hydration group was asked to increase water intake by 1 to $1.5 \mathrm{l}$ /day relative to their weight, gender, and $24 \mathrm{~h}$ urine osmolality, in addition to usual consumed beverages; the control group was asked to continue with usual fluid intake. After six weeks, the change in urine volume was significantly different between groups $(0.9 \mathrm{l} /$ day; $p=0.002)$ with no change in serum sodium and no serious adverse effects. Similarly, preliminary results of our large clinical trial of the same intervention (489 patients enrolled to date) demonstrated a significant separation be-
\end{abstract}

tween groups on $24 \mathrm{~h}$ urine volume (at 12 months the mean difference between groups was $1.2 \mathrm{l} / \mathrm{day} ; \mathrm{p}<0.001$ ) with no serious adverse effects. Serum sodium has remained stable in both groups over follow-up. To our knowledge, this trial is currently the largest of its kind to date; the significant separation between groups with respect to urine volume indicates that we will have scientifically reliable data on the effect of increased fluid intake on renal decline. The analysis of primary and secondary outcomes will be conducted at the conclusion of follow-up in July 2016.

Since life forms emerged from water to land, antidiuretic hormones have played an important role in ensuring water homoeostasis. The antidiuretic response appears to be an adaptation related to terrestrial habitat [1]. While essential for water regulation, antidiuretic hormones have vasoconstrictive effects that in the short term ensure a necessary intravascular volume for such vital issues as the flight and fight reaction, but in the long term have negative effects on renal hemodynamics, blood pressure, and ventricular function [2-4]. The antidiuretic

\begin{tabular}{|c|c|}
\hline KARGER 125 & $\begin{array}{l}\text { (c) } 2015 \text { S. Karger AG, Basel } \\
0250-6807 / 15 / 0667-0018 \$ 39.50 / 0\end{array}$ \\
\hline $\begin{array}{l}\text { E-Mail karger@karger.com } \\
\text { www.karger.com/anm }\end{array}$ & $\begin{array}{l}\text { This is an Open Access article licensed under the terms of the } \\
\text { Creative Commons Attribution-NonCommercial 3.0 Un- } \\
\text { ported license (CC BY-NC) (www.karger.com/OA-license), } \\
\text { applicable to the online version of the article only. Distribu- } \\
\text { tion permitted for non-commercial purposes only. }\end{array}$ \\
\hline
\end{tabular}

Dr. William Clark

London Health Sciences Centre

800 Commissioners Road East

A2-343, London, ON N6A 5W9 (Canada)

E-Mail william.clark@lhsc.on.ca 
hormone (vasopressin) infusion increases proteinuria, renal plasma flow, and hyper filtration, while the administration of vasopressin antagonists reduces proteinuria and lowers blood pressure $[2,4]$. Humans are normally antidiuretic, excreting urine with osmolality greater than plasma throughout most of the day and night. Ingestion of supplemental water to cause a water diuresis lowers the plasma level of vasopressin.

In the animal experimental model of chronic progressive kidney disease (5/6 nephrectomy), Professors Bouby and Bankir have demonstrated that increasing water intake suppresses vasopressin and reduces blood pressure, proteinuria, renal hypertrophy, glomerulosclerosis, and interstitial fibrosis [5]. A more recent study in this model of chronic progressive kidney injury has shown that the introduction of an antidiuretic hormone inhibitor was additive to renin angiotensin system blockade in providing increased kidney protection [4]. At present, there is conflicting evidence in human studies about the role of increased hydration on kidney function. An early retrospective analysis reported that higher urine volumes were associated with a faster decline in estimated glomerular filtration rate (eGFR); however, $75 \%$ of the patients had polycystic kidney disease and the association disappeared after controlling for diuretic and anti-hypertensive use [6].

Results from three additional studies (two cross-sectional and one longitudinal) suggest a potentially protective effect of greater water intake on kidney function. In a seven-year longitudinal study of 2,144 participants, we demonstrated that $24 \mathrm{~h}$ urine volume at baseline was associated with a slower decline in eGFR after adjusting for many potential confounders [7]. In two cross-sectional studies (one conducted in Australia and the other in the United States), low fluid intake and water intake, respectively, correlated with a higher prevalence of chronic kidney disease $[8,9]$. These studies offer support for the hypothesis that increased water intake slows progression of chronic kidney disease by lowering vasopressin levels and provide the biologic rationale for conducting a clinical trial. Prior to launching a randomized control trial on the effect of increased water intake on renal decline, we conducted a six-week pilot study to examine the safety and feasibility of asking adults with chronic kidney disease to increase their water intake by 1 to $1.5 \mathrm{l} /$ day [10]. We wished to address the issue of safety in view of clinician concerns about water intoxication in patients with chronic kidney disease [10]; also, with respect to feasibility, only one study with a pre- and post-study questionnaire showed that $11 \%$ of participants were unable to increase hydration, $35 \%$ produce daily urine volumes of less than $21 /$ day, and $30 \%$ reported that they were able to increase their water intake only during non-working hours [11]. For these reasons, as well as concerns about regression to the mean, we needed to test the feasibility of whether subjects coached to increase water intake versus those who were coached to maintain normal fluid intake, would have different urine volumes at the end of the pilot study [10]. Because increased hydration can decrease appetite and increase urination, particularly at night, which could negatively affect sleep patterns, we also compared groups on these measures and on their quality of life.

Twenty-nine adults with chronic kidney disease (an eGFR between 30 and $60 \mathrm{ml} / \mathrm{min} / 1.73 \mathrm{~m}^{2}$ and albuminuria [albumin:creatinine ratio $>2.8 \mathrm{mg} / \mathrm{mmol}$ for females and $>2.0 \mathrm{mg} / \mathrm{mmol}$ for males]) were placed in block sizes of 3 by computer-generated randomization to a hydration or control group in a 2:1 ratio. The hydration group $(\mathrm{n}=18)$ was asked to increase their water intake by 1 to $1.5 \mathrm{l} /$ day, relative to their weight, gender, and $24 \mathrm{~h}$ urine osmolality in addition to usual beverage intake for 6 weeks. The control group $(n=11)$ was asked to maintain normal fluid intake. To encourage adherence, research personnel made regular contact with participants and inquired about regimen tolerance and adherence to their prescribed water intake. Between baseline and six weeks, the $24 \mathrm{~h}$ urine volume of the hydration group increased by $0.7 \mathrm{l} /$ day (from 2.3 to $3.0 \mathrm{l} /$ day) and the $24 \mathrm{~h}$ urine volume of the control group decreased by $0.3 \mathrm{l} /$ day (from 2.0 to $1.7 \mathrm{l} /$ day). The change in urine volume was significantly different between groups $(0.9 \mathrm{l} /$ day; $\mathrm{p}=$ 0.002 ). We found no significant change in serum osmolality, sodium concentration, eGFR, or quality of life, and no serious events were reported nor observed. This pilot study demonstrated that patients with chronic kidney disease can successfully and safely increase their water intake by 1 to $1.5 \mathrm{l} /$ day over and above the usual fluid intake with no serious adverse effects [10]. Further, to validate the biologic plausibility of our hypothesis, we examined correlations with copeptin (a surrogate marker of vasopressin): at 6 weeks follow-up, copeptin was inversely correlated with both $24 \mathrm{~h}$ urine volume and eGFR [12]. These results prepared the way for our large randomized control trial of 700 participants with stage 3 chronic disease (the Water Intake Trial, WIT), which will determine whether increased water intake can slow the progression of chronic kidney disease (registered at ClinicalTrials.gov NCT01766687).

Since recruitment began in April 2013, we have enrolled 489 participants with chronic kidney disease from 


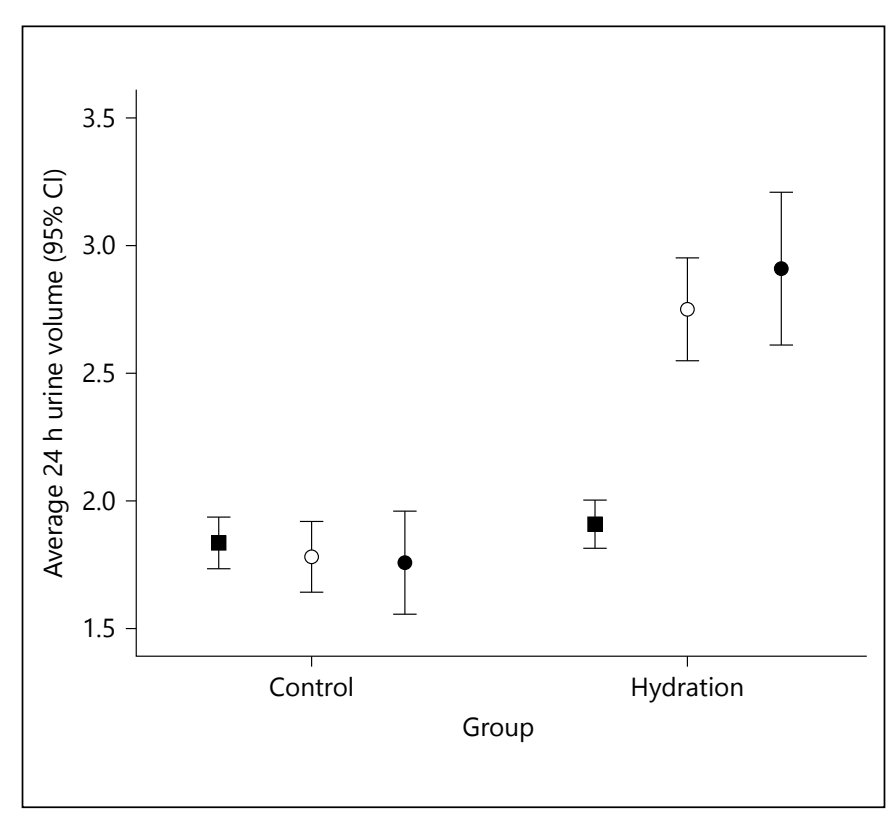

Fig. 1. Average $24 \mathrm{~h}$ urine volume (l/day) at baseline (black squares), 6 months (open circles), and 12 months (black circles).

clinics in London and Windsor (Ontario, Canada). Recruitment is expected to continue until July 2015. Data collection is going well with less than $2 \%$ missing data on key variables such as $24 \mathrm{~h}$ urine volume and eGFR. Study withdrawals presently are less than $10 \%$. The results of an interim analysis for safety and monitoring suggest excellent separation between groups; between baseline and 12 months follow-up, $24 \mathrm{~h}$ urine increased by $0.9 \mathrm{l} /$ day in the hydration group but remained stable among controls. The difference between groups at 6 months was $1.0 \mathrm{l} /$ day $(\mathrm{p}<0.001)$ and the difference between groups at 12 months was $1.21 /$ day $(\mathrm{p}<0.001)$ (fig. 1$)$. Similarly, between baseline and 9 months, the daily total fluid intake increased from $2.1 \mathrm{l} /$ day to $2.8 \mathrm{l} /$ day in the hydration group and remained stable in the control group at $2.01 /$ day (fig. 2). Serum sodium was similar between groups at all comparison points. These results indicate that (1) our coaching system is working, (2) participants in the hydration group are able to maintain an increased fluid intake over time with minimal regression to the mean, and (3) cross-group contamination in the control group is minimal. To our knowledge, this is now the largest randomized controlled trial of increased water intake in patients with chronic kidney disease. The successful separation between groups with respect to fluid intake and $24 \mathrm{~h}$ urine volume means that we will have scientifically reliable data

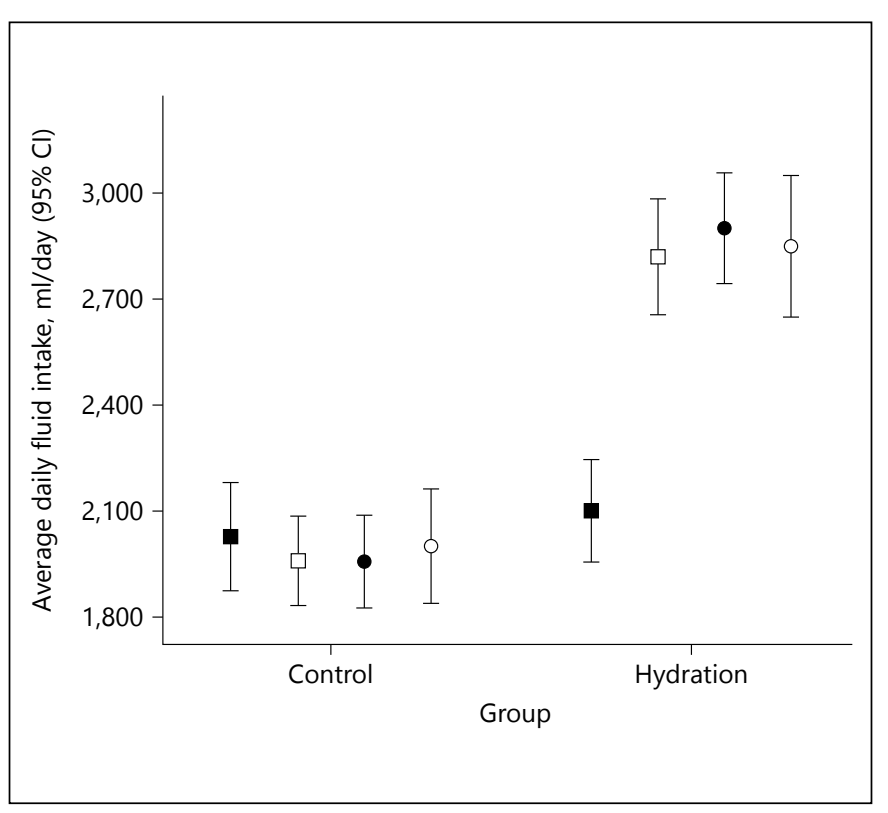

Fig. 2. Average daily fluid intake ( $\mathrm{ml} /$ day) at baseline (black squares), 3 months (open squares), 6months (black circles) and 9 months (open circles).

on the effect of increased fluid intake on kidney function, when we examine the primary and secondary outcome data at the conclusion of follow-up in July 2016.

\section{Disclosure Statement}

William Clark has received consulting fees or honorarium and support to travel to meetings from Danone Research. The Water Intake Trial (WIT) is funded by Danone Research. The study sponsors had no direct role in the data collection, statistical analysis, interpretation of the results, or drafting of the manuscript.
References

\footnotetext{
Ann Nutr Metab 2015;66(suppl 3):18-21
DOI: 10.1159/000381241

Ann Nutr Metab 2015;66(suppl 3):18-21
DOI: 10.1159/000381241
} 
5 Bouby N, Bachmann S, Bichet D, Bankir L: Effect of water intake on the progression of chronic renal failure in the 5/6 nephrectomized rat. Am J Physiol Renal Physiol 1990; 258:F973.

6 Hebert LA, Greene T, Levey A, Falkenhain ME, Klahr S: High urine volume and low urine osmolality are risk factors for faster progression of renal disease. Am J Kidney Dis 2003;41:962-971.

7 Clark WF, Sontrop JM, Macnab JJ, Suri RS, Moist L, Salvadori M, et al: Urine Volume and Change in Estimated GFR in a CommunityBased Cohort Study. Clin J Am Soc Nephrol 2011;6:2634-2641.
8 Strippoli GF, Craig JC, Rochtchina E, Flood VM, Wang JJ, Mitchell P: Fluid and nutrient intake and risk of chronic kidney disease. Nephrol 2011;16:326-334.

$\gg$ Sontrop JM, Dixon SN, Garg AX, BuendiaJimenez I, Dohein O, Huang SS, et al: Association between water intake, chronic kidney disease, and cardiovascular disease: A crosssectional analysis of NHANES data. Am J Nephrol 2013;37:434-442.
0 Clark WF, Sontrop JM, Huang S-H, Gallo K, Moist L, House AA, et al: The chronic kidney disease Water Intake Trial (WIT): results from the pilot randomised controlled trial. BMJ Open 2013;3:e003666.

11 Fuss M, Simon J, Fontinoy N, Coussaert E: High fluid-low calcium intake: not all renal stone formers adhere to this simple treatment. Eur Urol 1979;5:97-99.

12 Sontrop JM, Huang SS, House A, Gallo K, Buendia-Jimenez I, Vecchio M, et al: Effect of increased water intake on plasma copeptin in patients with chronic kidney disease; in : ISN World Congress of Nephrology. Cape Town, South Africa, 2015 